\title{
Social media and compliant financial promotions: An oxymoron?
}

\author{
Miah Ramanathan \\ Journal of Direct, Data and Digital Marketing Practice \\ (2013) 14, 340-342. doi:10.1057/dddmp.2013.24
}

Topic: Financial services

Who: The Financial Services Authority

Where: United Kingdom

When: 2013

Law stated as at: 26 February 2013

What happened

\section{Traditional media rules apply}

\section{The current financial promotions regime}

Companies are increasingly engaging with and utilizing social media outlets to generate new business, promote and strengthen their brand identity and interact with their customers. Financial services companies are, however, very much behind the curve as a result of stringent UK rules that govern the way in which financial services companies market their products and services to the public.

The current financial promotion regime under the Financial Services and Markets Act 2000 makes no distinction between forms of media - in fact, the Financial Services Authority (the 'FSA'), in a speech given in September 2012, confirmed that the application of the financial promotion rules is 'media-neutral'.

Therefore, rules designed to apply to static, traditional forms of media, such as print advertising, now apply to constantly evolving and dynamic new social media in the form of social networking sites, forums, blogs and smartphone apps.

Arguably as the existing regulatory environment - and with it the FSA - is reformed, this is the time for the Financial Conduct Authority (the 'FCA'), which will now be responsible for the supervision of financial promotions to re-evaluate the existing regime. It could look to create a better fit that will ultimately protect consumers and also encourage financial services companies to harness the potential commercial benefits associated with actively engaging with social media.

Under the current regime, companies are prohibited from communicating, in the course of business, any invitation or inducement to engage in investment activity unless: (a) the company has specific permissions from the FSA; (b) the content of the communication is approved by a company with such permissions; or (c) it falls within one of the exemptions under the Financial Services and Markets Act 2000 (Financial Promotion) Order 2005. In making such communications, companies must adhere to the mantra for financial 


\section{What the FSA thinks companies are doing wrong}

\section{US social media guidelines are useful}

promotions - 'fair, clear and not misleading' — and satisfy the conduct of business rules dictating the form and content of financial promotions, as set out in the FSA Handbook.

The FSA actively monitors the use of social media by financial services companies to promote their products and services and has identified a number of common examples of poor practice that companies can easily address:

- Promotions failing to set out the appropriate risk warnings in one go. Promotions should be 'stand-alone compliant' and if the space available for the advert is not sufficient for all of the required information and risk warnings, a company should not be tempted to try and rely on providing this information at a later stage instead. This includes website banner adverts and sponsored search engine results.

- If a company wishes to avoid the financial promotion rules and use an 'image advert' instead, such an advert must consist of only the name of the company, a logo or image associated with the company, the details of a point of contact and a reference to the types of products and services offered. Any additional content risks tripping the advert into the financial promotions regime.

- There is no 'one click rule', meaning that all of the required information must be set out together in one place and not solely accessible by clicking through to another webpage.

- Roll-over risk warnings on website banner adverts are not sufficient.

- Risk warnings must always be displayed prominently and clearly.

- Complex financial products and services should be promoted over a suitable social media outlet and not a 'tweet'.

- Given how long content can remain in circulation on the internet, companies should actively review their promotions to ensure that they remain accurate and compliant for as long as they remain in the public domain.

What is also helpful guidance for financial services companies is the 'Social Media: Consumer Compliance Risk Management Guidance' draft paper issued in the United States by the Federal Financial Institutions Examination Council (the 'FFIEC'). While the guidance issued by the FFIEC is aimed at the US market, it does point to some practical steps, which any company can take to utilize social media in a way that keeps the regulators happy:

- a clear strategy on the use of social media including the company's objectives, that is, promotion of its products and services, increasing brand awareness;

- policies and procedures setting out what is acceptable use of social media to ensure that the business understands which practices are and are not compliant with the applicable regulations;

- a documented process for selecting and managing relationships with third-party service providers, that is, website hosts, as the use of such 
Why this matters third parties will fetter a company's ability to control content relating to their business and their products and services; and

- an employee training programme to avoid misuse of social media.

'Digital media is very much on [the FSA's] radar'. What is very clear from the discussions our clients have had with the FSA is that the FCA intends to proactively and vociferously supervise firms and enforce the applicable regulations.

The use of social media by financial services companies should create interesting and, as yet, untapped, business opportunities and an everexpanding target audience that spans over generations and countries.

However, the risks of failing to comply with the financial promotion rules and any other applicable regulation governing the use of social media to promote products and services ranges from fines to public censure, which ultimately pose the risk of greater, long-term damage to a company's reputation.

Social media is developing at an exciting, unprecedented pace presenting new and innovative commercial opportunities. Navigating the regulations can be a minefield. However, done carefully, the use of social media opens up a whole host of opportunities for financial service companies.

\title{
Could new CAP behavioural rules apply to connected TV?
}

\author{
John Davidson-Kelly
}

Journal of Direct, Data and Digital Marketing Practice

(2013) 14, 342-344. doi:10.1057/dddmp.2013.25

Topic: Behavioural advertising

Who: CAP

Where: United Kingdom

When: 2013

Law stated as at: 7 February 2013

What happened

When the ASA and CAP announced new rules for third-party online behavioural advertising, effective from 4 February 2013, it may not have occurred to them that the new regime is wide enough to catch apps on connected TVs. Although the new rules are primarily intended to apply to the delivery of targeted advertising by ad networks, the rules are likely to apply to certain activities of operators of connected TV platforms or of other connected devices.

What is more, the strictest rule in the new code provisions, reserved for the most intrusive type of behavioural tracking and 